\title{
Exploring the affordances of WeChat for facilitating teaching, social and cognitive presence in semi-synchronous language exchange
}

\author{
Yuping Wang \\ School of Humanities, Languages and Social Science, Griffith University, Nathan, Australia \\ Wei-Chieh Fang \\ Department of Education, Washington University in St. Louis, St. Louis, USA
}

Julia Han

School of Humanities, Languages and Social Science, Griffith University, Nathan, Australia

\author{
Nian-Shing Chen \\ Department of Information Management, National Sun Yat-sen University, Kaohsiung, Taiwan
}

\begin{abstract}
This research is an exploratory study that evaluates the affordances of WeChat for the development of a community of inquiry (CoI) in semi-synchronous language exchange supported by WeChat. WeChat is an instant messenger that facilitates a multimodal environment in which interaction can happen synchronously, semi-synchronously and asynchronously through text, audio, video conferencing and a variety of pedagogically facilitating affordances. Differing from most existing studies in CoI, this research investigates all three presences in the CoI framework, that is, teaching, social, and cognitive presence, as they emerged in the language exchange between students of Mandarin Chinese and students of English. The findings from this research confirm the establishment of the three presences in CoI, but with features specific to WeChat-supported semi-synchronous language exchange. Recommendations for future research into CoI facilitated by WeChat are also put forward.
\end{abstract}

\section{Introduction}

In the last 10 years or so social software, also known as social media or Web 2.0 tools, have transformed not only how we live, but also how we learn. As far as language learning is concerned, social software is an ideal tool to extend traditional classroom learning to an online community in which students can improve their target language proficiency with their peers and even with native speakers in their own time. In Tian and Wang's (2010) words, social software can take "part of the learning outside the classroom and into the real world" (p. 194), and Thomas (2009) called this the decentralisation of "the role of the language classroom” ( p. 21).

McLoughlin and Lee (2007) defined Web 2.0 as “a second generation, or more personalised, communicative form of the World Wide Web that emphasises active participation, connectivity, collaboration and sharing of knowledge and ideas among users” (p. 665). Some popular examples of Web 2.0 tools are wikis, blogs, Facebook, Twitter and Skype - and the list goes on. Since 2008, mobile messaging apps have joined forces with other Web 2.0 tools to make social software even more ubiquitous and interactive. The engaging and motivating effects of Web 2.0 tools have been reported in the literature (see Liu, Wang, and Tai [2016] for a discussion). In terms of the modes of learning, we have been using synchronous and asynchronous to describe the degree of interactivity and instantaneity of the communication supported by these tools. However, we found that these two phrases were inadequate in describing the delayed transfer of real time audio and/or text exchanges facilitated by social media such as WeChat, a relatively new instant messenger. Different from audio and video conferencing, there is a longer time lag between sending and receiving text messages or audio files via the chat facility, although both parties are online at the same time. We thus coined a new phrase to capture the speed of such interaction, semi-synchronous, which is under investigation in this research.

The fit between social software and language learning has long been established in empirical studies (see Luo [2013] for a review), with most studies focusing on either synchronous or asynchronous interactions (e.g., Chen, Ko, Kinshuk, \& Lin, 2005; Lee, 2011; Mitchell, 2012; Tian \& Wang, 2010; Wang \& Chen, 
2009; Wang, Chen, \& Levy, 2010). Little has been published in regard to the fit between language learning and social software which supports semi-synchronous interaction. This lack of research initially prompted us to an evaluation of WeChat which seems to promise pedagogical potential for facilitating language learning in many ways, in particular, in supporting semi-synchronous interaction in a media rich environment. However to date, the use of WeChat to support language learning has not been reported in the literature. This research thus aims to bridge this gap by investigating learners' social and cognitive development and ways in which how such development is facilitated by the teacher in semi-synchronous WeChat supported language exchanges between students learning each other's first language.

To provide a comparatively complete picture of a study of this magnitude, the community of inquiry (CoI) framework (Garrison, Anderson, \& Archer, 2000) is adopted. This framework is specifically designed to identify teaching, social and cognitive presence in an online learning community. The adoption of this framework is further justified by the exploratory nature of this study, investigating the potential of WeChat to facilitate semi-synchronous language learning. The effectiveness of the CoI framework has been attested to in a variety of disciplinary studies, mostly in explaining learning in asynchronous and text-based online discussions. However, it has not been sufficiently researched in synchronous, let alone, semi-synchronous learning, and its application in language learning is scarce. This research hopes to contribute to the understanding of $\mathrm{CoI}$ in the context of semi-synchronous language learning through the evaluation of a WeChat-supported language exchange between Mandarin and English students in two universities.

\section{Literature review}

The CoI framework was first proposed by Garrison, Anderson and Archer in 2000 as a process model for analysing text-based asynchronous online discussions. Essentially, the framework adopts a collaborative constructivist approach to online learning, drawing upon Dewey's (1933) educational philosophy, in particular the idea that "an educational experience must fuse the interests of the individual and society, that individual development was dependent upon community” (Swan, Garrison, \& Richardson, 2009; p. 45). According to this framework, worthwhile educational experience occurs within the community through the interaction of three core elements - cognitive, social and teaching presence, as shown in Figure 1. As a generic model, this framework has been applied to many disciplinary studies in higher education and has proved to be an effective model for the exploration of learning processes and the characteristics of asynchronous text-based learning.

\section{Community of Inquiry}

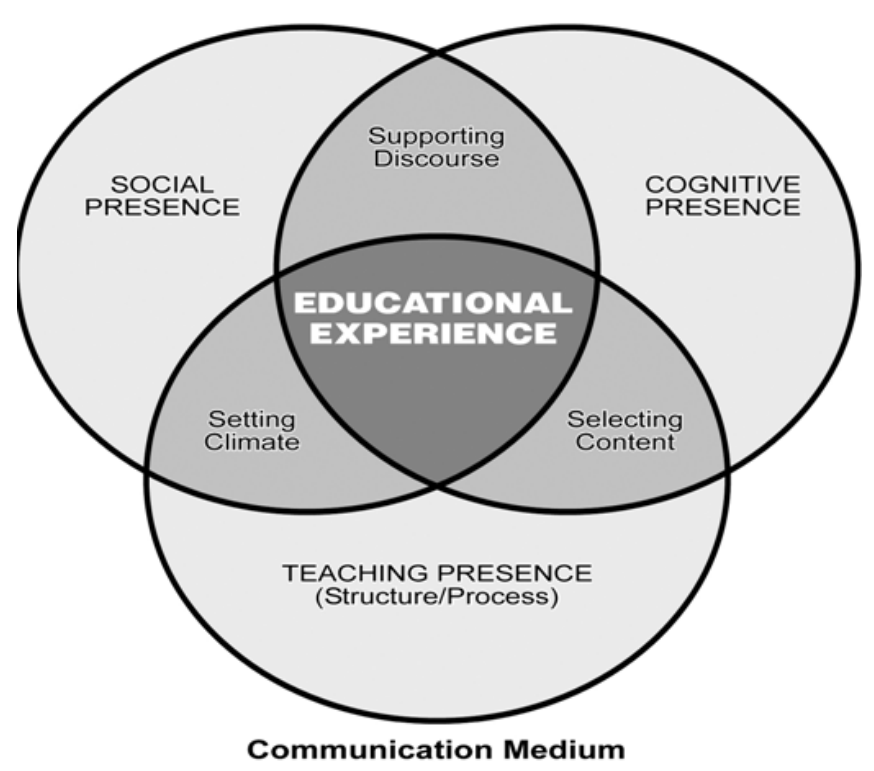

Figure 1. The CoI framework (Garrison, Anderson, \& Archer, 2000; p. 88)

Cognitive presence is defined as "the extent to which the participants in any particular configuration of a community of inquiry are able to construct meaning through sustained communication” (Garrison, 
Anderson, \& Archer, 2001; p. 89). Consistent with this idea, Ramsden (1988) argued that the opportunity to negotiate meaning, diagnose misconceptions and challenge accepted beliefs, as in the community of inquiry described by Lipman (1991), is essential for deep and meaningful learning experiences. More specifically, meaning is negotiated through a staged process of "the exploration, construction, resolution and confirmation of understanding through collaboration and reflection in a community of inquiry" (Garrison, 2007; p. 65). However, research investigating cognitive presence suggests that there is a tendency to not reach the stage of resolution in online asynchronous text-based discussion (Garrison, Anderson, \& Archer, 2000; Garrison, Anderson, \& Archer, 2001; Kanuka, Rourke, \& Laflamme, 2007; Rourke \& Kanuka, 2009; Vaughan \& Garrison, 2005). The current study explores this tendency further in the context of semi-synchronous language learning.

Garrison (2007) defined social presence as “the ability to project one's self and establish personal and purposeful relationships" with other members of the community for better cognitive development (p. 63). The degree of social presence is often measured by how effectively community members express themselves and how they interact and collaborate with one another.

Teaching presence in the CoI framework is operationalised as "the design, facilitation and direction of cognitive and social processes for the purpose of realizing personally meaningful and educationally worthwhile learning outcomes” (Anderson, Rourke, Garrison, \& Archer, 2001; p. 5). Thus the essential issues in teaching presence are the roles that a teacher should play and the degree to which a teacher should be involved in the online community of inquiry.

Since the CoI framework was proposed in 2000, many empirical studies have adopted and tested this framework from different angles. In 2010, The Internet and Higher Education journal published a special issue called The Community of Inquiry Framework: Ten Years Later. Many of the articles in this issue reexamined the framework and identified issues needing more sophisticated investigation (see Garrison, Anderson, \& Archer, 2010). One such issue is the relationship and interaction between the three elements of CoI.

Examining the three elements from a systems perspective (e.g., Bertalanffy, 1968; Waddington, 1977; Waldrop, 1992), we contend that the three elements are dynamically interdependent upon each other and that they should form a positive feedback loop. That is, the three elements never stop evolving and the changes in one element affect the other two elements. It is the constant interaction among the three elements that invigorates learning. While the dynamic nature of CoI has not received much academic attention, the mutual dependency of the three elements has been partially recognised by CoI scholars. For example, Garrison, Anderson and Archer (2000) pointed out that "social presence has a facilitating effect on cognitive presence, as it directly supports the process of critical thinking carried out by the participants,” (p. 89) and that cognitive presence is "more easily sustained when a significant degree of social presence has been established” (p. 95). Indeed, Garrison (2007) also promoted the idea that "[t]he purpose of social presence in an educational context is to create the conditions for inquiry and quality interaction (reflective and threaded discussions) in order to collaboratively achieve worthwhile educational goals” (p. 64). These arguments suggest that both teaching and social presence play a supporting and complementary role in cognitive presence. Garrison and Arbaugh (2007) also drew our attention to a complementary relationship between teaching presence and cognitive presence. Garrison and Cleveland-Innes (2005) confirmed the impact of teaching presence on learners' engagement in course content. Swan, Garrison and Richardson (2009) concluded that "[t]eaching presence is established by attending to cognitive and social presence challenges in a collaborative CoI” (p. 54). These studies suggest the existence of a correlation between the three elements, but the majority of CoI related empirical studies have usually focused on one element of the framework, either cognitive, social or teaching presence. Few have investigated the relationship among the three elements in one study, as neatly pointed out by Garrison and Arbaugh (2007) in their review of the CoI literature. They stated that, "to date there are very few studies that examine the three elements of the framework simultaneously, either quantitatively or qualitatively” (p. 159).

The study by Shea et al. (2010) pushes the CoI research agenda a step forward, by confirming a strong correlation between instructor teaching presence and student social presence, and between instructor social presence and student social presence. However, it did not examine the correlation between cognitive, social and teaching presence. A more recent study by Borup, West, Thomas, and Graham (2014) confirms the effectiveness of video feedback at establishing instructor social presence, claiming that videos provide a 
more affective context in which emotional expression, closeness, and natural and open communication can be achieved.

Our literature review also indicates that the framework has been applied mostly to studies on asynchronous, text-based discussions or forums. Only a few earlier studies have explored the existence of social presence in online synchronous interaction as demonstrated in online collaborative learning (e.g., Chou, 2002; Mercer, 2003), but "the presence of all three elements in online synchronous learning environments remains relatively unknown” (Ling, 2007; p. 155). Ling’s study narrows this gap by applying the CoI framework to the analysis of synchronous interaction in online text chats in an IT course, thereby confirming the existence of the three elements in synchronous online learning.

With the exception of the studies by Pawan, Paulus, Yalcin, and Chang (2003), and Arnold and Ducate (2006), in comparison with other disciplinary studies, another relatively unexplored area in the use of the CoI framework is online language learning. Pawan et al. (2003) found that without explicit teaching presence, online discussion tended to become less interactive and often led to serial monologues without reaching resolution. In contrast, Arnold and Ducate (2006) confirmed the emergence of a high degree of interactivity in both cognitive and social presence in asynchronous online discussion. Wei, Chen, and Kinshuk (2012) also reported the same results in their study of social presence in online classrooms. They concluded that the topics which were chosen seemed to have determined the level of interactivity. CoI research into semi-synchronous and synchronous interaction in language learning is still missing. Thus this current research seeks to contribute to CoI research by filling in these gaps.

\section{Methodology}

\section{Overview of the study}

The language exchange was conducted on WeChat over one semester in semester 1 in 2014, pairing two groups of students, one from a third year Mandarin class at an Australian university and the other consisting of students learning English at a university in Taiwan. The online exchange aimed to provide students with more exposure to authentic language input, and more chances for target language output outside the classroom. There were a total of 30 mature aged participants, with 14 females and 16 males. Each pair formed their own private WeChat group. To access the interaction data and observe the exchange, the teachers had to enrol themselves into each group. In addition to an ice-breaker activity in the first week of the exchange, students were required to complete five mega tasks, one every other week (for examples of the task and task design, see table 1 . Consent to use the data in this study was obtained from all participants, and all participants' anonymity was protected by numbering the participants, instead of using their real names. While the exchange was an extracurricular activity for the English students, it formed part of the course activities for the Mandarin students, attracting $10 \%$ of their total marks for the semester.

In terms of organisation, a student handbook was provided to each student at the beginning of the exchange, detailing the objectives of the project, the tasks to be completed, instructions for task completion, and a step-by-step manual for using WeChat. A list of strategies for managing the exchange effectively was also emailed to the students. Class discussions were conducted each week so that students could report their language exchange experiences.

\section{Research questions}

As this is an exploratory study evaluating the pedagogical affordances of WeChat in facilitating online language exchange, we adopted the CoI framework to provide a panoramic view of how students and teachers interacted in such a learning environment. Therefore data were solicited and analysed to answer the following three research questions:

1. In what ways does WeChat facilitate teaching presence in semi-synchronous language exchange?

2. In what ways does WeChat facilitate social presence in semi-synchronous language exchange?

3. In what ways does WeChat facilitate cognitive presence in semi-synchronous language exchange? 


\section{The technology used for the language exchange - WeChat}

WeChat was chosen as a medium for the language exchange for a number of pedagogical reasons. It is a free application, which literally means micro message. As an instant messenger, it offers potential for supporting asynchronous, semi-synchronous and synchronous collaboration and interaction, as it allows for one-to-one, one-to-many and many-to-many text and voice messages to be exchanged in real time. Its latest version also supports live one-on-one video conferencing. WeChat also facilitates ubiquitous learning as it can be installed on smartphones, laptops, desktop computers and other handheld devices. It can be used as a platform for sharing large amounts of information via text, audio and video files with both individuals and groups, leaving a short message, or starting a conversation both through text and audio chat. The chat can be facilitated by photos, stickers, videos and links, all on the same interface. WeChat also supports a variety of languages, such as English, Chinese, Korean, Hindu and Spanish. Chinese characters can be written by hand or typed into the text chat box using Pinyin. The in-app translation feature is a new addition that supports the translation of up to 20 languages. Another feature with potential pedagogical value is its push feed service, which can send large amounts of information to subscribers via its public accounts. Figure 2 shows the self-explanatory and user-friendly WeChat interface. New users do not need any formal training to be able to manage this interface.

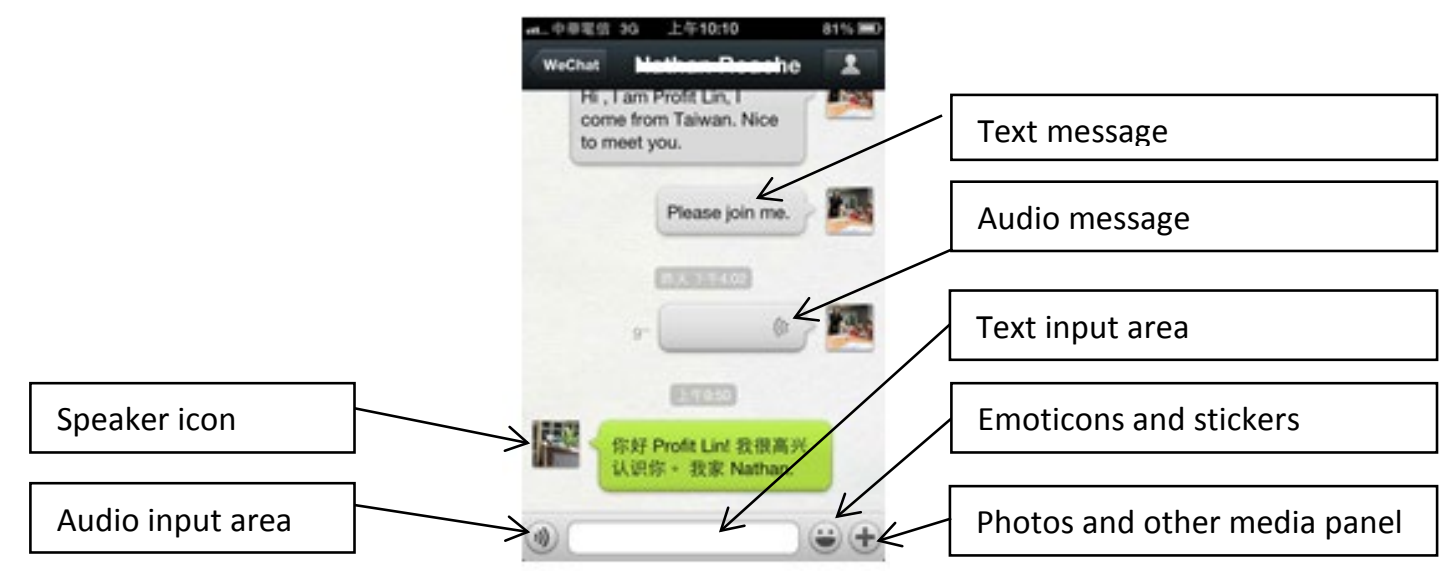

Figure 2. WeChat chat interface

\section{Tasks and task design rationale}

Tasks for this language exchange were designed by one of the researchers in the current study in close consultation with the teachers involved in the two groups. There were one ice-breaker activity and five mega tasks. The ice-breaker activity was scheduled for the first week of the exchange to provide students with a chance to introduce themselves (see Table 1 for suggested activities for the Mandarin group).

Table 1

The ice breaker activity

\begin{tabular}{|c|c|c|}
\hline Week & Topics & Suggested activities \\
\hline 1 & $\begin{array}{l}\text { Getting to know each other } \\
\text { (you can talk about your } \\
\text { interests and hobbies, your } \\
\text { family members, your } \\
\text { personality, your studies etc.). }\end{array}$ & $\begin{array}{l}\square \text { Send an audio greeting to your language partner (LP) } \\
\text { in Chinese. } \\
\square \text { Write a short self-introduction in characters and send } \\
\text { it to your LP. } \\
\square \text { Chat about your interests, hobbies etc. via audio in } \\
\text { Chinese. } \\
\square \text { Set up a schedule for the exchange. }\end{array}$ \\
\hline
\end{tabular}

In the initial design, the five open-ended mega tasks each contained three sub tasks, a recorded speech, a semi-synchronous dialogue and form-focused feedback from language partners. Each of the three sub-tasks had its own pedagogical focus and took advantage of different WeChat features (see Table 2). The recorded speech made use of the voice chat feature of WeChat for recording a 2 to 3 minute speech prepared by the students in advance in the target language. The rationale for this asynchronous task was to allow students to focus on accuracy of grammar, pronunciation and tones. The task design deliberately utilised the semi- 
synchronous voice chat in WeChat to require the students to exchange conversation-like voice messages, and to engage in 30 minutes of real time oral interaction. It was hypothesised that, in comparison to synchronous conversations, more accurate output would be generated in semi-synchronous dialogues, as this would allow students with a little more time to organise their output while waiting for their partner's responses. Furthermore, we hoped that semi-synchronous interaction would function as scaffolding for synchronous conversation, as most of the participants had not yet achieved an advanced level of speaking proficiency in their target languages. As for the form-focused feedback, students were instructed to provide initial comments via voice chat only on the use of language, in particular, on the problematic use of the language by their language partners in both the prepared speech and the semi-synchronous conversation. Further discussion or clarifications of the feedback could be conducted either through text or voice chat at the students' own discretion. Table 2 shows an example of the task design for weeks 3 and 4.

Table 2

Suggested topics and activities for weeks 3 and 4

\begin{tabular}{|c|c|c|}
\hline Week & Topics & Suggested activities \\
\hline $3-4$ & Talking about a trip/holiday. & $\begin{array}{l}\square \text { Recorded speech: Verbally introduce the most } \\
\text { impressive or worst travel experience you've had. } \\
\square \text { Conversation: Have a chat about the things that you } \\
\text { don't wish to happen during a trip. } \\
\square \text { Form-focused feedback (provide some feedback on } \\
\text { each other's language, including usage and grammar). }\end{array}$ \\
\hline
\end{tabular}

Based on students' feedback suggesting that a 30-minute semi-synchronous conversation was too hard to manage due to time zone differences and other commitments, and in order to improve students' writing skills, we replaced the semi-synchronous conversation with the submission of a 100 word written text via text chat, and required students to provide written feedback (see Table 3).

Table 3

Revised activities for weeks 7 and 8

\begin{tabular}{lll}
\hline Week & Topics & Suggested activities \\
\hline $7-8$ & Talking about & 1. Recorded speech: Verbally introduce your \\
& movies/songs/singers/actors. & favourite movie stars. \\
& 2. Provide some feedback on each other's language \\
& use. \\
& $\square \quad$ 1. Writing task: Send your language partner a written \\
& passage (around 100 words) about what TV \\
& programs/drama series are popular in \\
& Australia/Taiwan. \\
& 2. Provide some feedback on each other's language \\
& use. \\
\hline
\end{tabular}

\section{Data collection}

Our research questions and the small number of participants determined that we adopt a qualitative approach to data collection and analysis. To be more specific, in order to explore teaching, cognitive and social presence in sufficient depth and in the specific context of the semi-synchronous learning environment supported by WeChat, we believed that a qualitative inquiry with more concrete evidence would reveal what happened during the process of the development of the three presences. Such an investigation is particularly important to this exploratory study as the WeChat-supported learning context is still new to us. This also required us to employ multiple data in order to both examine the diversity of such a learning context and to verify the findings. Table 4 illustrates the data collected in answer to each research question. 
Table 4

Data referring to each research question

\begin{tabular}{lll}
\hline Research question & Data source \\
\hline $\begin{array}{l}\text { 1. WeChat affordances regarding } \\
\text { teaching presence }\end{array}$ & $\bullet$ & Task designer's reflection journals on task design \\
& $\bullet$ & Teachers' reflection journal on task organisation \\
& $\bullet$ & Student survey data \\
\hline 2. WeChat affordances regarding & $\bullet$ & The use of media in WeChat \\
$\quad$ social presence & $\bullet$ & Transcriptions of corrective feedback \\
\hline 3. WeChat affordances regarding & $\bullet$ & Transcriptions of interactional discourses \\
& & \\
\hline
\end{tabular}

\section{Data analysis}

Qualitative analysis was performed to examine the multiple groups of data. Such analysis was largely guided by the CoI framework, and its operational categories and indicators relating to each presence were used as a coding template (see Table 5).

Table 5

CoI categories and indicators, adapted from Garrison and Anderson (2003)

\begin{tabular}{lll}
\hline Elements & Categories & Indicators (examples only) \\
\hline Teaching Presence & Design \& Organisation & setting curriculum \& activities; \\
& Facilitating Discourse & shaping constructive exchange; \\
& Direct Instruction & focusing \& resolving issues. \\
\hline Social Presence & Affective Expression & self-projection/expressing emotion; \\
& Open Communication & trust/risk free climate; \\
& Group Cohesion & collaboration/interactivity. \\
\hline Cognitive Presence & Triggering Event & sense of puzzlement; \\
& Exploration & information exchange; \\
& Integration & connecting ideas; \\
& Resolution & application. \\
\hline
\end{tabular}

To answer research question 1 regarding the teaching presence, we analysed the task designer's reflections to gain an understanding of the task design rationale, with the purpose of exploring how this rationale could help build teaching presence. The reflections of one English teacher and two Mandarin teachers on facilitating the language exchange process were also analysed to see the degree of teacher involvement. This descriptive analysis was then supported by comments elicited from the student survey.

In answering research question 2, WeChat's facilitation of social presence, the use of media such as emoticons and stickers as well as the transcriptions of peer interaction and collaboration were the focus of analysis. Stickers are illustrations of characters, pictures, or animals, often animated, that are shared during online chats to show how one is feeling and to liven up the chats. This analysis focused on indicators of social presence put forward by Garrison and Anderson (2003) such as affective expressions and group cohesion indicated by peer feedback on language use.

With regard to research question 3, cognitive presence facilitated by WeChat, we focused on a discourse analysis of the interaction between the students. Given that the categories (i.e., triggering event, exploration, integration and resolution) identified for CoI by Garrison and Anderson (2003) are more for assessing cognitive presence in critical thinking than in L2 acquisition, we adopted the Varonis and Gass discourse model (1985) for a more accurate account of cognitive presence in our language exchange. Although this model was proposed over 30 years ago, it has been utilised in many fairly recent studies to identify and analyse occasions of interactional modification in L2 acquisition in Computer Assisted Language Learning (e.g., Wang, 2006). Interactional modification is defined by Chapelle (2001) as "interruption of a communication exchange due to a breakdown in comprehension and a subsequent attempt to recover from breakdown” (p. 49). It has long been regarded as “a candidate for a necessary (not sufficient) condition for acquisition” (Larsen-Freeman \& Long, 1991; p. 144).

Thus according to the Varonis and Gass (1985) model, there are two parts in an occasion of interactional modification - a trigger and a resolution, which consists of four functional primes. The first prime is the 
trigger which can be an "utterance or portion of an utterance on the part of the speaker which results in some indication of non-understanding on the part of the hearer" (Varonis \& Gass, 1985; p. 74). The second part of the model, the resolution, is made up of the other three primes: an indicator, signalling nonunderstanding, a response to the indicator, and a reaction to the response. This model was applied to our analysis of the interactional routines as an indicator of cognitive presence.

\section{Results}

The results of this study presented and analysed to indicate the establishment of a CoI as evidenced in the emergence of teaching, social and cognitive presences in WeChat-supported language exchange. Under each presence, a combination of data was explored to reveal the affordances specific to the presence in question.

\section{Teaching presence}

Three groups of data were analysed to depict teaching presence. These data are the reflections from the task designer and the teachers, and feedback from the students.

\section{Task designer's reflections}

The designer kept detailed reflections on the rationale for task design and on later modification of the tasks in accordance with students' feedback. For example, the initial feedback collected through a class discussion revealed mixed feelings about the semi-synchronous conversation through the exchange of voice chat. On one hand, two students mentioned that it was hard to manage because of their busy daily schedule and the differences in time zones. On the other hand, all the students who had completed the semisynchronous conversation task agreed that the semi-synchronous nature of the task facilitated the development of their speaking proficiency. This was reflected in 18B's comment that "I could have sufficient time to repeatedly listen to what my partner said and think about what to say. Besides, it keeps the conversation flow in a way that is not too fast or too slow.”

On consideration of these findings, we redesigned the last three mega tasks to replace the semi-synchronous conversation with a written passage focusing on encouraging peer feedback on the written task. This eased the demand on students to be online at the same time and also provided students with a chance to practise their writing skills. As a result, more feedback and more accurate output emerged, as shown in our transcripts of the chat records (see Figure 5).

With regard to task facilitation, although the teachers were enrolled in each student group and could join the students at any time, our teachers chose not to be involved in task completion to avoid interruption. However, we did implement two interventions following students' feedback and on the basis of our observation. We first intervened by emailing both groups the strategies for "getting the most out of your online exchange”. In accordance with the issues that we observed, in brief we suggested that students should:

- $\quad$ check their WeChat messages at least once a day and reply as soon as possible;

- learn to be a helpful tutor and provide as much feedback as possible;

- $\quad$ ask their language partner to repeat and/or explain anything they did not understand;

- $\quad$ ask their language partner to express the same thing in different words, if failing to understand;

- $\quad$ not be afraid of making mistakes;

- $\quad$ correct each other's mistakes; and

- $\quad$ speak clearly at a normal speed.

The second intervention was the requirement for students to report their WeChat exchange in class. We spent a few minutes each week in our face-to-face tutorials, discussing issues that emerged from the language exchange. The Mandarin teacher reported that such discussions were very useful in helping students with their problems, monitoring progress in task completion and gauging learning outcomes. 


\section{Teachers' reflections}

At the end of the exchange, a reflection journal was sent to the three teachers involved to elicit their feedback. The overall task design was appreciated by all three teachers. Of particular interest is the confirmation of the necessity for an ice-breaker activity at the start of the language exchange to "build up a good rapport among partners" (the English teacher, with the agreement of the two Mandarin teachers). The English teacher also reflected that "the topics in the tasks might be too broad to talk about" and suggested that tasks "start from specific questions to more open-ended discussion" as students became more familiar with each other and with the learning environment.

In regard to task organisation, all three teachers believed that training students to effectively manage the conversation in the target language was an important part of the teaching presence. The English teacher directed us to the need "to build up learners' "strategic competence" such as the knowledge of knowing how to ask questions, rephrase and get the messages across in different ways" and suggested that this training be conducted in class and before the start of the exchange. He also endorsed classroom discussions about the students' WeChat experiences after the completion of each task. He argued that "[o]nce learners are asked to share in class, they have the need to participate in and go deeper into the topics," and this "in return might lead to more language use." The in-class discussion was initially suggested by one of the Mandarin teachers who believed that this would be an effective way to check and assess students' progress in the language exchange.

\section{Data from the student survey}

In regard to teaching presence, one student commented in the survey that he felt a bit embarrassed with the teacher being in the group. In terms of student feedback on task types, the majority of students preferred the recorded speech and the writing task in comparison to the semi-synchronous conversation, as reflected in 4A's comments on the benefits of the language exchange: "I liked being able to prepare and say the recorded speeches - helped in fluency and communicating an idea. Writing was also good for incorporating new words/vocab we've learned in class.” Similar comments were also made by two other students.

\section{Social presence}

The data discussed here relate to the three indicators of social presence identified by Garrison and Anderson (2003): self-projection/expressing emotion, trust/risk free climate and collaboration and interaction. When discussing self-projection/expressing emotion and the trust/risk free climate, students' use of the media facilitated by WeChat was summarised and analysed. To indicate the level of interactivity and collaboration, transcriptions of peer feedback were analysed.

\section{The use of media in WeChat}

Emoticons, photos, stickers and hyperlinks were the four features most frequently used to express emotion and enhance a sense of trust and create a friendly atmosphere. Table 6 summarises the media used, in terms of frequency, examples and purpose of use. 
Table 6

The use of media

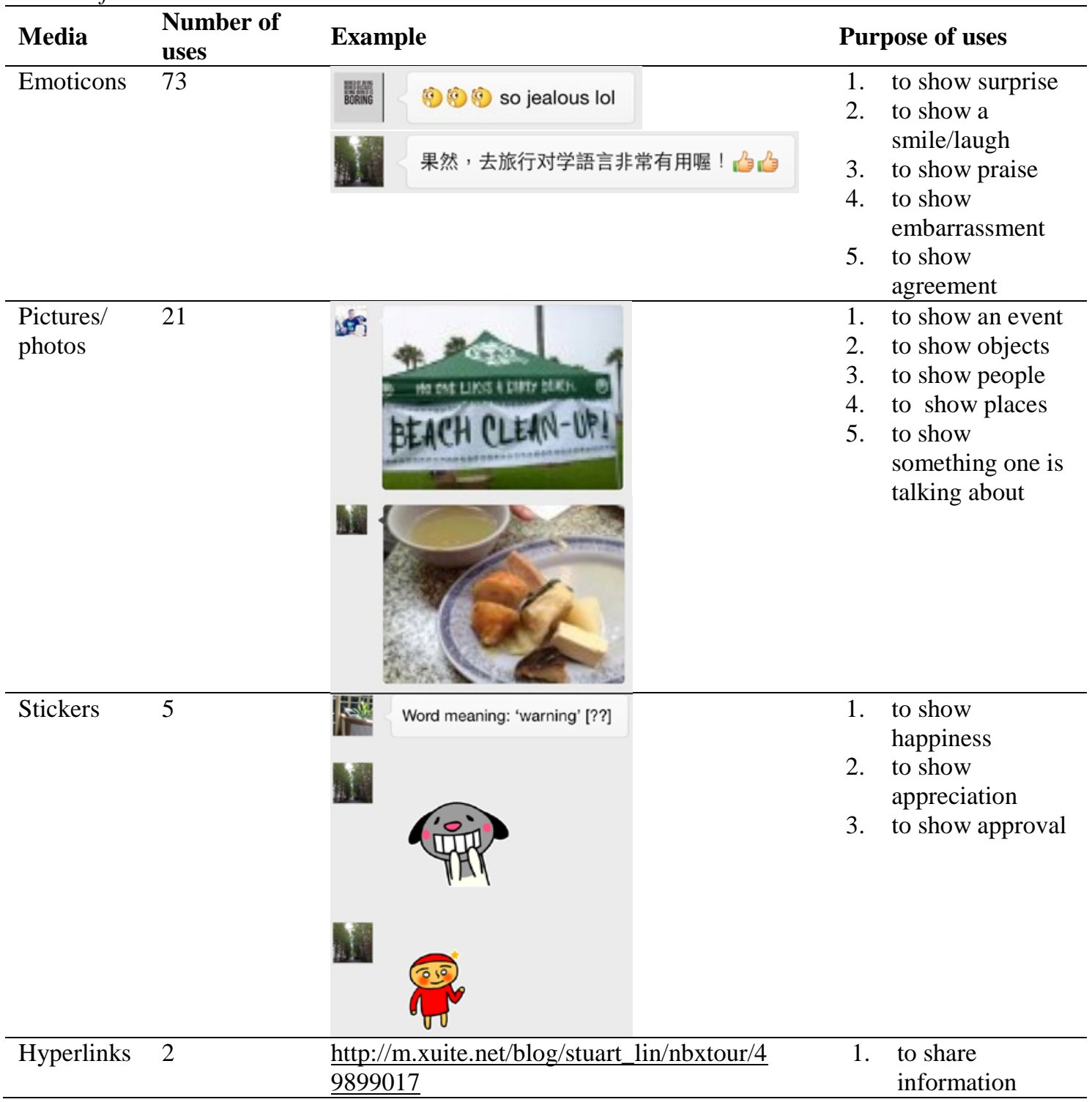

As shown in Table 6, emoticons were used most extensively, followed by photos. Among the emoticons, smiling faces and thumbs-up were used most frequently. Surprisingly, stickers were not employed on as many occasions as expected, although our data show that more stickers were used towards the end of the exchange as students became familiar with each other. There are hundreds of expressive stickers freely available on WeChat which could have been used more frequently and creatively. Only 9 out of the 15 pairs used these, with Pair 6 leading far ahead of all the other students, as shown in Table 7 - Media use by individual pairs. 
Table 7

Media use by individual pairs

\begin{tabular}{lllll}
\hline Pair & Emoticons $^{\mathbf{1}}$ & Stickers $^{\mathbf{2}}$ & Pictures/photos & Links \\
\hline 3 & 1 & 0 & 1 & 1 \\
6 & 47 & 4 & 10 & 0 \\
8 & 0 & 0 & 1 & 1 \\
9 & 6 & 0 & 0 & 0 \\
12 & 3 & 0 & 0 & 0 \\
15 & 1 & 0 & 0 & 0 \\
16 & 1 & 0 & 0 & 0 \\
17 & 9 & 0 & 7 & 0 \\
18 & 5 & 1 & 2 & 0 \\
\hline Total & 73 & 5 & 21 & 2 \\
\hline
\end{tabular}

${ }^{1}$ e.g., :)

2 e.g., a bunch of flowers

Transcriptions of corrective feedback

Collaboration and interaction are the inherent processes of the language exchange, and these were further promoted by the task design in our project. To be more specific, the provision of corrective feedback to each other was explicitly requested in the task design and therefore characterised the collaboration and interaction between language partners. Feedback was offered in either text or audio chat, focusing on grammar, pronunciation and tones. Figures 3, 4 and 5 are prime examples.

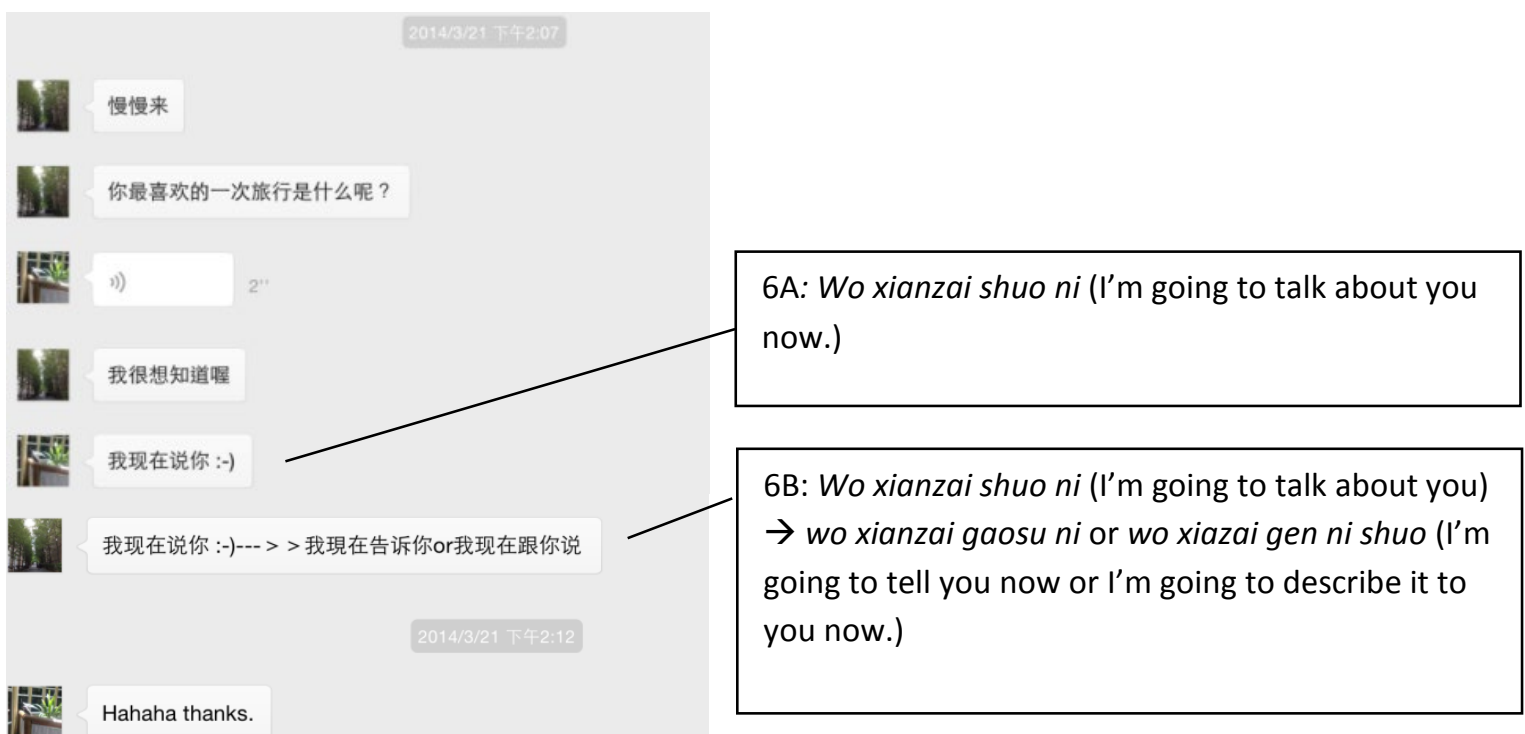

Figure 3. Corrective feedback through text chat

As shown in Figure 3, 6A wanted to say "I am going to tell you now" but what he rendered in Mandarin means "I am going to talk about you now." Participant 6B corrected him explicitly by offering two ways to say "I am going to tell you now," in Mandarin, as shown in the text after the arrow sign. After which, 6A showed his understanding and appreciation by saying "Hahaha, thanks". 


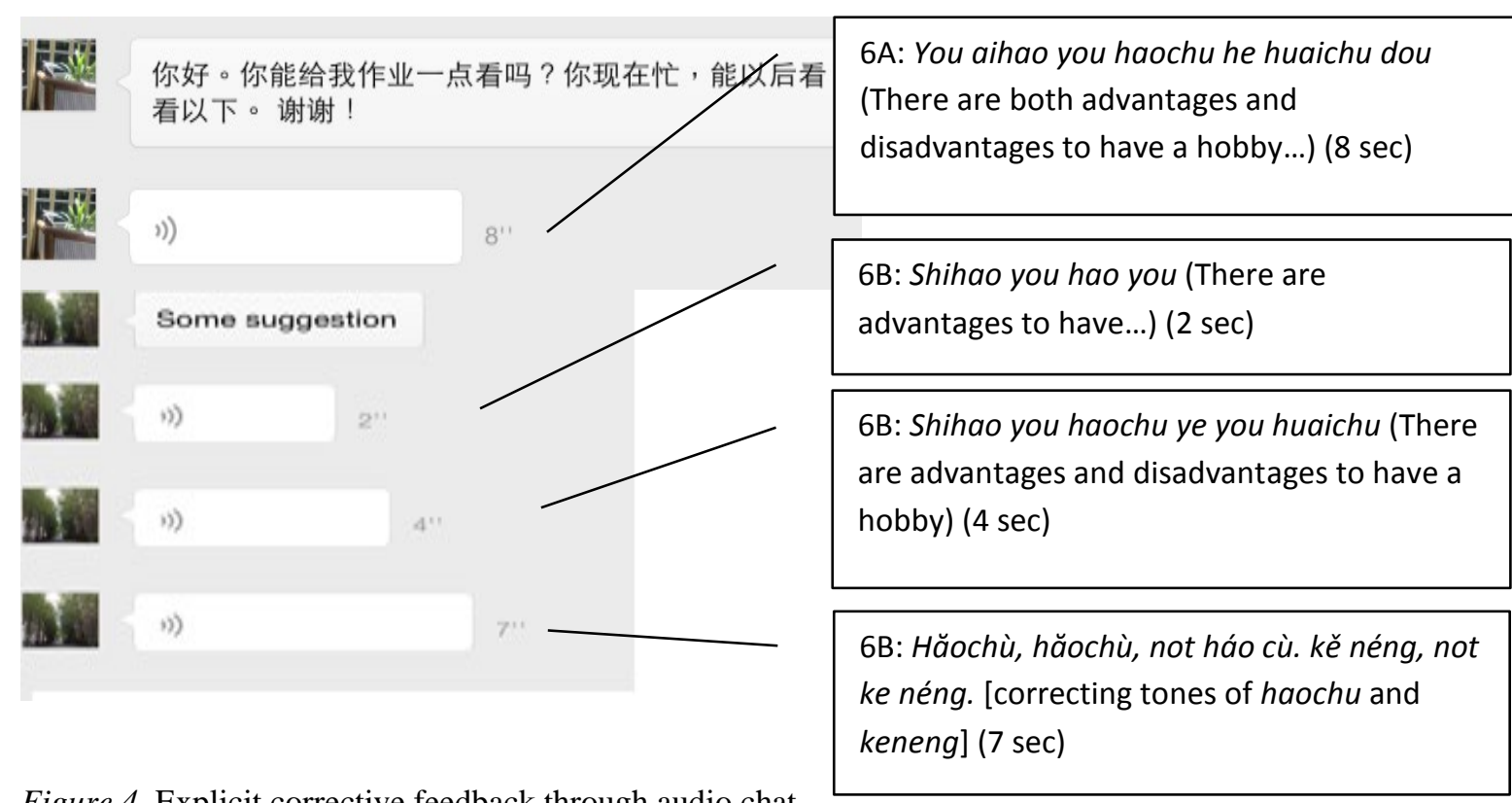

Figure 4. Explicit corrective feedback through audio chat

In Figure 4, 6A made a grammatical error when trying to say that there were both advantages and disadvantages to having a hobby, and 6B corrected the error in her first two audio messages and spoke the correct sentence at a slower than normal speed. In the third audio message, she corrected 6A's pronunciation and tones by repeating haochu to show the correct pronunciation and tones.

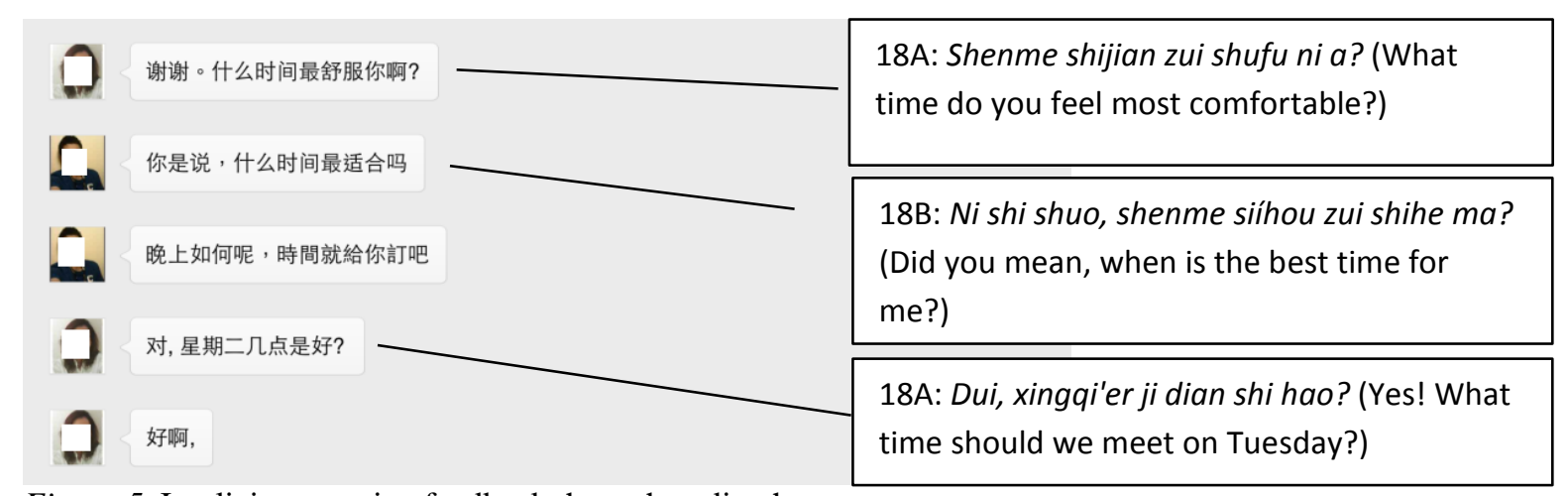

Figure 5. Implicit corrective feedback through audio chat

Figure 5 exemplifies implicit corrective feedback when 18B elicited: "Did you mean when the best time is for me?” after hearing 18A using shufu (comfortable) instead of heshi (suitable). Participant 18A confirmed by saying dui (yes, that's correct).

However, one student commented in the survey that it was "extremely uncomfortable being paired with a total stranger from a different culture who speaks a different language," and another mentioned that he/she felt awkward in speaking Chinese as they did not know each other well. Two Mandarin students suggested that they be paired with native speakers from the same university so that they could meet physically on a regular basis.

\section{Cognitive presence}

In comparison to the text-based discussion reported in the CoI literature, cognitive presence in WeChatsupported language exchange exhibited some unique characteristics: occasions of interactional modification often leading to resolution, alternate use of text and audio chat and overlapping interactional routines. Figures 6 to10 exemplify these features. 
As shown in Figure 6, in this instance of interactional modification, the negotiation of meaning was triggered by lihai, an unknown word to 6A who signalled his non-understanding by asking for the meaning of the word explicitly. In Line 3, 6B was still answering 6A's previous question about the advantage of travelling, and in Line 4, 6A repeated lihai to draw 6B's attention. In Line 5 and 6, 6B responded by providing two examples of lihai to illustrate the meaning of brilliant. Resolution was reached in Line 7 by $6 \mathrm{~A}$ as he confirmed his understanding with "Ah, ok, thanks”. Occasions of interactional modification also occurred in audio exchanges and resolution was often reached.

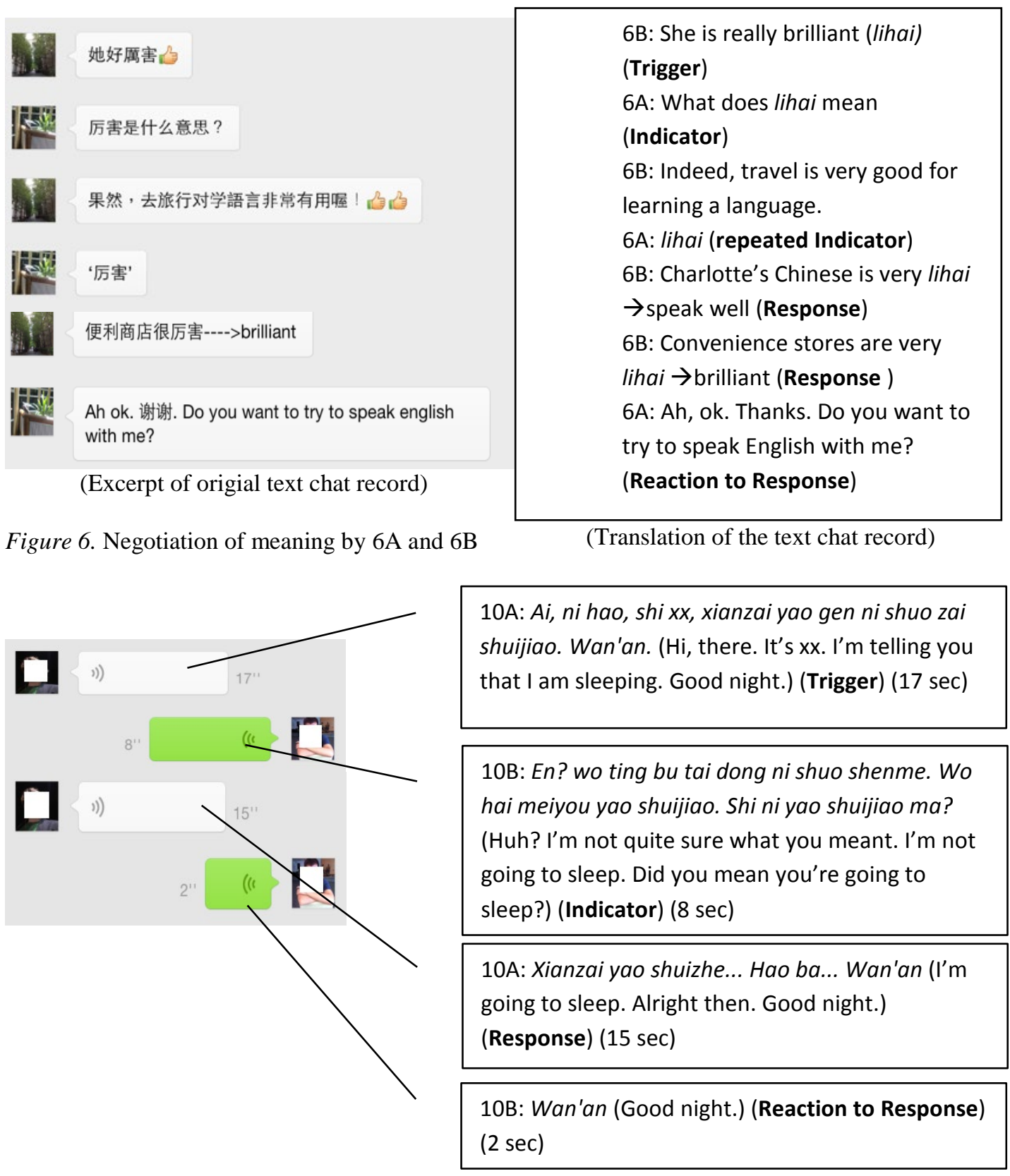

Figure 7. Negotiation of meaning by $10 \mathrm{~A}$ and $10 \mathrm{~B}$

Figure 7 is an example of negotiation of meaning via voice chat. The trigger for non-understanding was the incorrect use of grammar by10A who said he was sleeping by using zai where he really wanted to say that he was going to bed and should have used yao. 10B indicated his non-understanding by asking whether $10 \mathrm{~A}$ meant that he was going to bed by using yao. 10A confirmed by responding with yao, and 10B reacted by saying wan'an (good night), thus reaching a resolution of this negotiation of meaning. 
Figure 8 and 9 demonstrate another feature of the WeChat exchange - alternate use of text and audio chat. 18B in Figure 8 typed both Chinese characters and Pinyin to reply to 18A's audio statement that she did not know how to say "Maltese" in Chinese. The writing of the characters and Pinyin on the screen for the word "Maltese" better facilitated the acquisition of this word than audio alone. 18A used audio to thank 18B. 2A in Figure 9 asked 2B, through audio chat, to talk about his American trip but 2B failed to understand. 2A then repeated what she said orally by typing characters in the text chat box for better understanding.

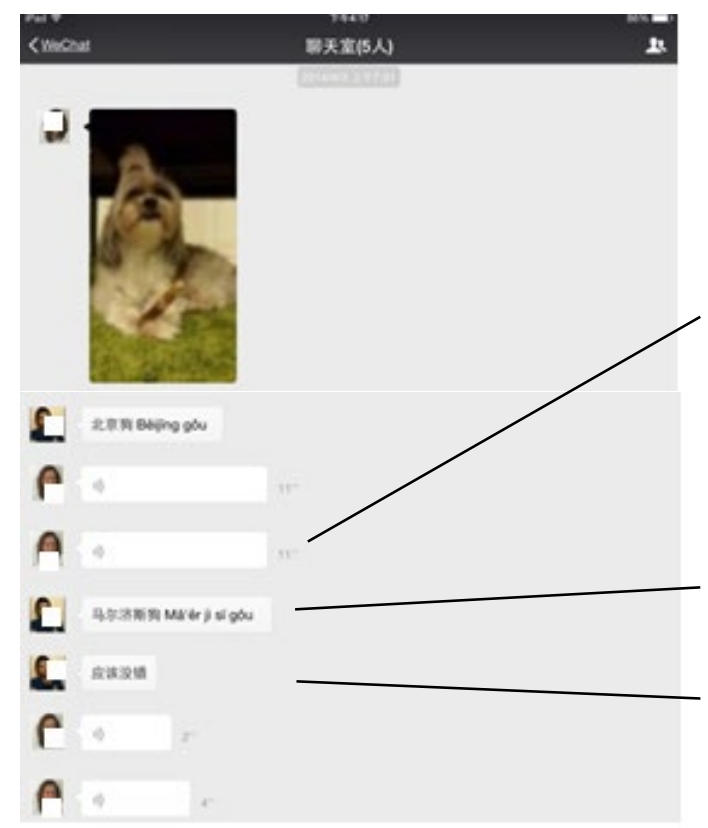

18 A: Ta bu shi Beijing gou. Ta ...wo bu zhidao zhongwen. Ta shi Maltese...er... (She's not a Beijing dog. She ... I don't know how to say it in Chinese... She is Maltese.) (11 sec)

18 B: Mă’ěr jí sī gŏu (Maltese)

18 A: Xiexie ni. (Thank you.) (2 sec)

Figure 8. Alternate use of text and audio chat

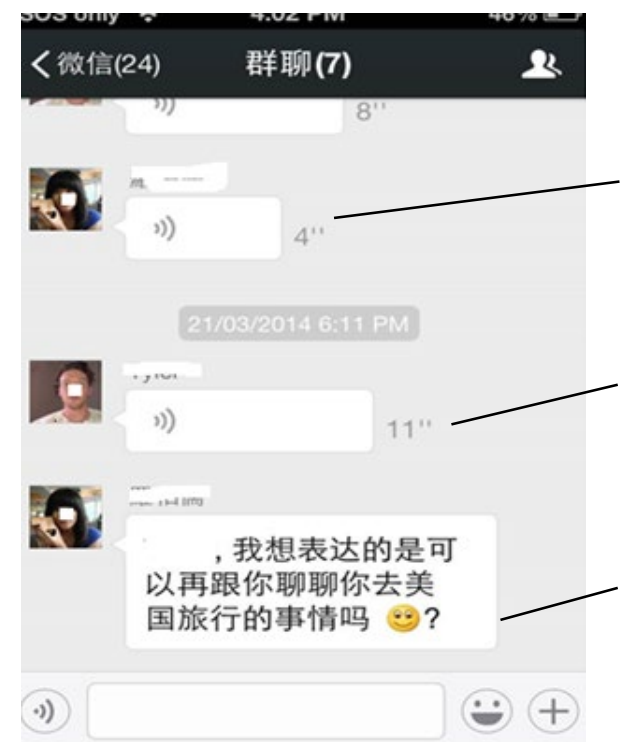

2A: Ni keyi zai liaoliao ni qu meiguo fasheng de shiqing ma? (Can you talk about your trip to the US?)(4 sec)

2B: Wo chabuduo ting de dong le, buguo wo tingbudong. (I almost understood you, but I don't really.) (11sec)

2A: What I wanted to say was to chat a bit more with you about your American trip (-).

Figure 9. Alternate use of text and audio chat 


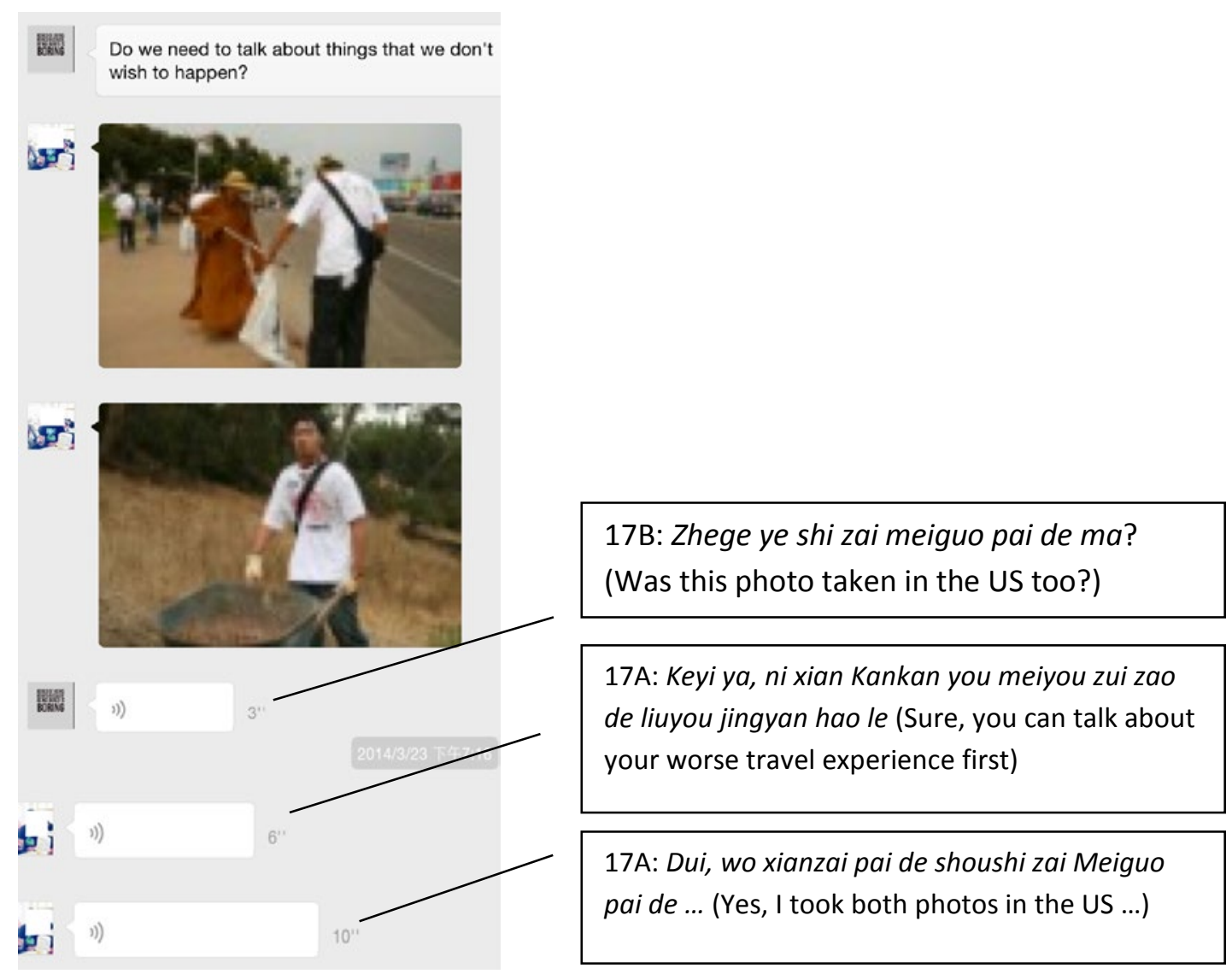

Figure 10. Overlapping interactional routines

Overlapping interactional routines emerged as another characteristic of the cognitive presence as shown in Figure 10.17B initiated the exchange by saying “Do we need to talk about things we don't wish to happen”, while 17B uploaded two photos. Seeing the photos, 17B asked via audio chat if the photos were taken in the US. In the next turn, 17A answered 17B's first question using audio chat, saying that they could talk about their worst travel experiences. He then moved on to answer 17B's second question by saying that both photos were taken in the US. The overlapping did not seem to cause confusion. Such overlapping happened quite regularly in both text and audio chats (also see Figure 6), due to the time lag in the process of recording/typing and transmission. Usually the second question or comment had been posted when the language partner was still commenting on a previous exchange. Sometimes two conversation threads could go on for a while but they did not often hinder understanding, and students seemed to be able to follow each thread with ease. Students may have become used to overlapping in text chat as text chats have become part our daily lives.

\section{Discussion and implications for future research}

The findings presented above are discussed further here in reference to the development of teaching, social and cognitive presences. This discussion will lead to suggestions for future research into each presence.

\section{Teaching presence}

Due to the nature of language exchange, teachers did not facilitate the actual task completion directly. Teaching presence was thus more manifest in task design and organisation. In terms of task design, the reflections of from the task designer and the teachers direct us to the need to adjust task design in accordance with our increased understanding of the affordances of the tools used. In our research, we replaced the semisynchronous conversations with a writing task, partly due to the need to explore WeChat's affordance for developing writing skills. However, this adjustment did not allow us to further explore the facilitating effect of the semi-synchronous interaction on developing learners' conversational and interactional competence, 
although such effect was not only commended by students, but was also observed in the recordings of such conversations. This finding urges us to further examine the potential of semi-synchronous interaction in a longitudinal study. In particular, a comparative study to explore the differences between synchronous language exchange (e.g., Tian \& Wang, 2010, Wang \& Tian, 2013) and semi-synchronous language exchange could shed light on many significant issues in L2 acquisition.

With regard to the organisation of the language exchange, our data indicate that teachers could facilitate cognitive and social presence through a number of measures. That is, before the online exchange, teachers could help prepare students for the exchange by training them to be linguistically, socially, pedagogically and technologically ready for the exchange. Linguistically, teachers could "scaffold the tasks by first giving students some structured or specific issues to talk about, and then as the mutual understanding develops, provide more open-ended discussion,” as suggested by the English teacher. In our study, although the topics were all covered in the semester's curriculum, the open task and the lack of teaching presence did lead to student output of varying quality and quantity. Social strategies for how to manage effective language exchange should be provided to students, such as how to keep the conversation moving forward and how rapport can be developed, especially with the use of the media provided by WeChat, such as the stickers and photos. Pedagogically, as students play the roles of teachers to each other, they should be trained in basic pedagogy for effective interaction. This can include ways of explaining language points, strategies to encourage output and clear articulation and pronunciation. Technologically, the functionalities of the tools to be used should be practised in class so that students can use the tools adeptly and creatively to engage more deeply in learning.

Although teaching presence was constrained by the nature of language exchange, its importance in facilitating social and cognitive presence was confirmed in this research. Furthermore, WeChat proved to be able to afford opportunities for more teacher involvement during task completion, as teachers can join the chat group at any time to offer guidance. Another useful tool for teachers to facilitate learning is the Moment, a public area where text files and photos with captions can be uploaded, and commented on by community members. It can be used as an ongoing measure to discuss issues emerging from language exchange.

\section{Social presence}

The results clearly indicate that social presence can be easily established in the WeChat environment. This is partly due to the collaborative nature of language exchange tasks which require students to interact with each other both semi-synchronously and asynchronously. Such a high level of interactivity forms a distinct contrast to the lack or low level of interactivity between students in asynchronous text-based discussions which have been reported in CoI studies (e.g., Garrison, Anderson, \& Archer, 2001; Meyer, 2003; PenaShaff \& Nicholls, 2004). Another factor contributing to the establishment of social presence is the friendly and lively environment afforded by the various features (see Tables 6 and 7) in WeChat, such as the audio and text chat integrated into one interface, and a variety of stickers and emoticons. Clearly, these media helped to create a trusting, relaxed and friendly environment for the online exchange. Without these media, the exchanges could be less lively and not as rich.

One limitation of this research is that our task design did not specifically require students to use media features, especially the use of stickers, to enhance their social presence. Nor did the teachers introduce these features to the students, although this could have been an effective way to facilitate social and cognitive presence.

In terms of supporting social presence, future research could also investigate the function of group chat, where students can form different interest groups and move from group to group if they choose to, in accordance with individual needs and interests. Another feature facilitating a strong social presence is the Moment, where students can post their opinions for everyone to see and comment on.

\section{Cognitive presence}

Our findings also point to two characteristics unique to WeChat-supported cognitive presence, which might lead to improved learning outcomes. Firstly, in contrast to asynchronous text-based negotiation for meaning, it seems easier for our students to reach the resolution stage. This probably can be explained by 
the fact that interactional modifications in language learning were caused more by linguistic nonunderstanding than content-related non-understanding which can be more complicated and less specific to deal with. Secondly, also relating to the above point, WeChat's affordance of the choice of using either audio or text chat, or both, on the same interface makes negotiating for meaning more effective and lively, as students could use the text to confirm/reinforce what was said or heard (see Figure 3). This unique feature of WeChat could contribute to effective learning outcomes. As Garrison, Anderson, and Archer (2001) rightly pointed out, "[t]he extent to which cognitive presence is created and sustained in a community of inquiry is partly dependent upon how communication is restricted or encouraged by the medium” (p. 93). Another function of WeChat that we did not investigate is Favourite, where favourite messages can be stored and retrieved for later use. This feature could be explored in future research in order to gain an understanding of its pedagogical value for cognitive development, such as using it as a personal learning space for retrievable learning resources.

To summarise, the CoI framework has proven to be effective not only in documenting evidence in regard to WeChat affordances for supporting teaching, social and cognitive presence, but also in revealing the relationship between the three elements. Our findings confirm what has been reported in the CoI literature (e.g., Swan, Garrison, \& Richardson, 2009) regarding the facilitation of both cognitive and social presence by teaching presence. Such facilitation was achieved through effective task design, guidance on the side, and intervention when problems arose. This is true even when teachers were not directly involved in task completion. The media richness of WeChat also created a positive social environment for cognitive development. However, the scope of this study did not allow us to go further to explore more complicated relationships and interactions between these three presences, for example, the causal relationship between the changes in one presence and those in the other two. A longitudinal study is needed to observe such a dynamic relationship through a systems approach.

\section{Conclusion and future research}

By adopting the CoI framework, this exploratory study has made important theoretical and empirical contributions to our understanding of WeChat-supported language exchange. It has also directed us to issues that could be further investigated in future research.

Theoretically, this study has advanced the CoI research agenda in three major aspects. Firstly, the current study has expanded the scope of CoI research from mainly investigating asynchronous text-based interaction to semi-synchronous text- and audio-based interaction. Secondly, our study has strengthened language learning research in $\mathrm{CoI}$ which has been dominated by studies in other disciplinary areas. These two underexplored areas have long been recognised by CoI scholars (Garrison \& Arbaugh, 2007; Ling, 2007) but nevertheless have been insufficiently researched. Thirdly, by investigating the three elements of the CoI framework simultaneously, this research has enhanced our understanding of the relationships between the three elements and has directed our attention to the need to research their relationships through a systems approach. As an exploratory study, this research represents a starting point in investigating CoI in WeChat facilitated language learning. Many worthwhile issues still remain untouched. For example, in such a learning environment, does a higher level of cognitive presence require a lower level of teaching presence? Would the dynamic changes in one element cause corresponding changes in the other two? Does high quality cognitive presence promote effective social presence as has been proved the other way round? A longitudinal research study designed from a systems-based perspective is needed to answer these questions and to push CoI research forward.

Empirically, this research provides a comparatively comprehensive picture of the affordances of WeChat in supporting language exchange, shedding light on the uniqueness of such learning. While this research confirms the user-friendliness and highlights the fit between the media richness of WeChat and language learning, it also recommends that other pedagogically sound functions of WeChat be further explored in the future, such as group chat, the Favourite and the Moment. This initial study suggests that WeChat could be a useful tool in supporting language learning and its potential needs to be further explored. 


\section{Acknowledgements}

We would like to acknowledge the funding support for this research from the School of Languages and Linguistics Research Opportunities Grant Scheme 2014, Griffith University. We would also like to thank our colleagues Dr Sarah Prestridge and Dr Sorrel Penn-Edwards from Griffith Institute for Educational Research for providing valuable feedback on the earlier draft. Our thanks also go to Griffith Institute for Educational Research for engaging Dr Gillian Warry to proof read the manuscript. This research was also supported by Ministry of Science and Technology in Taiwan under project numbers NSC 101-2511-S-110003-MY3, MOST 103-2511-S-110-002-MY3.

\section{References}

Anderson, T., Rourke, L., Garrison, D. R., \& Archer, W. (2001). Assessing teacher presence in a computer conferencing context. Journal of Asynchronous Learning Networks, 5(2), 1-17. Retrieved from http://auspace.athabascau.ca/handle/2149/725

Arnold, N., \& Ducate, L. (2006). Future foreign language teachers' social and cognitive collaboration in an online environment. Language Learning \& Technology, 10(1), 42-66.

Bertalanffy, L. V. (1968). General system theory. New York, NY: Braziller.

Borup, J., West, R. E., Thomas, R., \& Graham, C. R. (2014). Examining the impact of video feedback on instructor social presence in blended courses. The International Review of Research in Open and Distributed Learning, 15(3), 232-256.

Chapelle, C. A. (2001). Computer applications in second language acquisition: Foundations for teaching, testing and research. Cambridge, UK: Cambridge University Press.

Chen, N.-S., Ko, H.-C., Kinshuk, \& Lin, T. (2005). A model for synchronous learning using the Internet. Innovations in Education and Teaching International, 42(2), 181-194. http://dx.doi.org/10.1080/14703290500062599

Chou, C. C. (2002, January). A comparative content analysis of student interaction in synchronous and asynchronous learning networks. Paper presented at the 35th Hawaii International Conference on System Sciences, New York. http://dx.doi.org/10.1109/HICSS.2002.994093

Dewey, J. (1933). How we think (Rev. ed.). Boston, MA: D.C. Heath.

Garrison, D. R. (2007). Online community of inquiry review: Social, cognitive, and teaching presence issues. Journal of Asynchronous Learning Networks, 11(1), 61-72.

Garrison, D. R., \& Anderson, T. (2003). E-learning in the 21st Century: A framework for research and practice. New York, NY: RoutledgeFalmer.

Garrison, D. R., Anderson, T., \& Archer, W. (2000). Critical inquiry in a text-based environment: Computer conferencing in higher education. The Internet and Higher Education, 2(2-3), 87-105. http://dx.doi.org/10.1016/S1096-7516(00)00016-6

Garrison, D. R., Anderson, T., \& Archer, W. (2001). Critical thinking, cognitive presence and computer conferencing in distance education. American Journal of Distance Education, 15(1), 7-23. http://dx.doi.org/10.1080/08923640109527071

Garrison, D. R., Anderson, T., \& Archer, W. (2010). The first decade of the community of inquiry: A retrospective. The Internet and Higher Education, 13(1-2), 5-9. http://dx.doi.org/10.1016/j.iheduc.2009.10.003

Garrison, D. R., \& Arbaugh, J. B. (2007). Researching the community of inquiry framework: Review, issues, and future directions. The Internet and Higher Education, 10(3), 157-172. http://dx.doi.org/10.1016/j.iheduc.2007.04.001

Garrison, D. R., \& Cleveland-Innes, M. (2005). Facilitating cognitive presence in online learning: Interaction is not enough. American Journal of Distance Education, 19(3), 133-148. http://dx.doi.org/10.1207/s15389286ajde1903_2

Kanuka, H., Rourke, L., \& Laflamme, E. (2007). The influence of instructional methods on the quality of online discussion. British Journal of Educational Technology, 38(2), 260-271. http://dx.doi.org/10.1111/j.1467-8535.2006.00620.x

Larsen-Freeman, D., \& Long, M. H. (1991). An introduction to second language acquisition research. London, UK: Longman.

Lee, L. (2011). Blogging: Promoting learner autonomy and intercultural competence through study abroad. Language Learning \& Technology, 15(3), 87-109. 
Ling, L. H. (2007). Community of Inquiry in an online undergraduate information technology course. Journal of Information Technology Education, 6, 153-168.

Lipman, M. (1991). Thinking in education. Cambridge, UK: Cambridge University Press.

Liu, C., Wang, P., \& Tai, S. (2016). An analysis of student engagement patterns in language learning facilitated by Web 2.0 technologies. ReCALL, 28(2), 1-19. http://dx.doi.org/10.1017/S095834401600001X

Luo, T. (2013). Web 2.0 for language learning: Benefits and challenges for educators. International Journal of Computer-Assisted Language Learning and Teaching, 3(3), 1-17. http://dx.doi.org/10.4018/ijcallt.2013070101

McLoughlin, C., \& Lee, M. J. W. (2007). Social software and participatory learning: Pedagogical choices with technology affordances in the Web 2.0 era. Proceedings of ascilite Singapore 2007 ICT: Providing choices for learners and learning (pp. 664-675). Retrieved from http://www.dlcubc.ca/wordpress_dlc_mu/educ500/files/2011/07/mcloughlin.pdf

Mercer, N. (2003). The educational value of 'dialogic talk' in 'whole class dialogue' New Perspectives on Spoken English in the Classroom: Discussion Papers (pp. 73-76). London, UK: Qualifications and Curriculum Authority.

Meyer, K. A. (2003). Face-to-face versus threaded discussions: The role of time and higher-order thinking. Journal of Asynchronous Learning Networks, 7(3), 55-65.

Mitchell, K. (2012). A social tool: Why and how ESOL students use Facebook. CALICO Journal, 29(3), 471-493.

Pawan, F., Paulus, T. M., Yalcin, S., \& Chang, C.-F. (2003). Online learning: Patterns of engagement and interaction among in-service teachers. Language Learning \& Technology, 7(3), 119-140.

Pena-Shaff, J. B., \& Nicholls, C. (2004). Analysing student interactions and meaning construction in computer bulletin board discussions. Computers \& Education, 42(3), 243-265. http://dx.doi.org/10.1016/j.compedu.2003.08.003

Ramsden, P. (Ed.). (1988). Improving learning: New perspectives. London, UK: Kogan Page.

Rourke, L., \& Kanuka, H. (2009). Learning in communities of inquiry: A review of the literature. International Journal of E-Learning \& Distance Education, 23(1), 19-48.

Shea, P., Hayes, S., Vickers, J., Gozza-Cohen, M., Uzuner, S., Mehta, R., Valtcheva, A., \& Rangan, P. (2010). Corrigendum to "A re-examination of the community of inquiry framework: Social network and content analysis.” Internet and Higher Education, 13(1), 10-21. http://dx.doi.org/10.1016/j.iheduc.2009.11.002

Swan, K., Garrison, D. R., \& Richardson, J. C. (2009). A constructivist approach to online learning: the Community of Inquiry framework. In C. R. Payne (Ed.), Information technology and constructivism in higher education: Progressive learning frameworks (pp. 43-57). Hershey, PA: IGI Global.

Thomas, M. (2009). Handbook of research on Web2.0 and second language learning. Hershey, PA: IGI Global Reference. http://dx.doi.org/10.4018/978-1-60566-190-2

Tian, J., \& Wang, Y. (2010). Taking language learning outside the classroom: Learner's perspectives of eTandem learning via Skype. The Journal of Innovation in Language Learning and Teaching, 4(3), 181-197. http://dx.doi.org/10.1080/17501229.2010.513443

Varonis, E. M., \& Gass, S. M. (1985). Non-native/non-native conversation: A model for negotiation of meaning. Applied Linguistics, 6(1), 71-90. http://dx.doi.org/10.1093/applin/6.1.71

Vaughan, N., \& Garrison, D. R. (2005). Creating cognitive presence in a blended faculty development community. The Internet and Higher Education, 8(1), 1-12. http://dx.doi.org/10.1016/j.iheduc.2004.11.001

Waddington, C. (1977). Tools for thought. New York, NY: Basic Books.

Waldrop, M. M. (1992). Complexity: The emerging science at the edge of order and chaos. London, UK: Viking.

Wang, Y. (2006). Negotiation of meaning in desktop videoconferencing-supported distance language learning. ReCALL, 18(1), 122-146. http://dx.doi.org/10.1017/S0958344006000814

Wang, Y., \& Chen, N.-S (2009). Criteria for evaluating synchronous learning management systems: Arguments from the distance language classroom. Computer Assisted Language Learning, 22(1), 118. http://dx.doi.org/10.1080/09588220802613773

Wang, Y, Chen, N.-S., \& Levy, M. (2010). The design and implementation of a holistic training model for language teacher education in a cyber face-to-face learning environment. Computers and Education, 55(2), 777-788. http://dx.doi.org/10.1016/j.compedu.2010.03.010 
Wang, Y., \& Tian, J. (2013). Negotiation of meaning in multimodal tandem learning via desktop videoconferencing. International Journal of Computer Assisted Language Learning and Teaching, 3(2), 41-55. http://dx.doi.org/10.4018/ijcallt.2013040103

Wei, C.-W., Chen, N.-S., \& Kinshuk. (2012). A model for social presence in online classrooms. Educational Technology Research and Development, 60(3), 529-545. http://dx.doi.org/10.1007/s11423-012-9234-9

Corresponding author: Nian-Shing Chen, nschen@mis.nsysu.edu.tw

Australasian Journal of Educational Technology (c) 2016.

Please cite as: Wang, Y., Fang, W-C., Han, J., \& Chen, N-S. (2016). Exploring the affordances of WeChat for facilitating teaching, social and cognitive presence in semi-synchronous language exchange. Australasian Journal of Educational Technology, 32(4), 18-37. 